\title{
Quality care means valuing care assistants, porters, and cleaners too
}

\section{P Toynbee}

Qual Saf Health Care 2003;12(Suppl 1):i13-i15

All too often, the focus of the very clever strategy papers produced in the upper reaches of the health department is on the next grand plan. Some of these reforms have been catastrophic for the quality of service that patients experience at ward level. Of these, the contracting out culture introduced in the 1980s and the 1990s has been the worst. Researching my book, Hard work-life in low pay Britain, I took six jobs at around the minimum wage, including work as a hospital porter, as a hospital cleaner, and as a care assistant. These are jobs at the sharp end, up close and very personal to the patients, strongly influencing their experiences of the services they were using. Yet they are low paid, undervalued jobs that fall below the radar of the policy makers. In hospitals they need to be brought back in-house and integrated into a team ethos. Paying these people more would cost more, but it would also harvest great rewards by using their untapped commitment.

See end of article for author's affiliation

.....................

Correspondence to: P Toynbee, The Guardian, 119 Farringdon Road. London ECIR 3ER, UK; p.toynbee@ guardian.co.uk t has taken some two decades, but at last there is a glimmer of recognition that what happens at the bottom in hospitals and care homes matters too. Floors do not clean themselves: dirt drags down the health, safety, and reputation of hospitals. These days it can lose them precious league table stars.

Porters matter too, patients' experience of a hospital stay may have less to do with whether their surgeon is cutting edge or average, than on whether gentle people are considerate and helpful in navigating the maze of clinics and procedures that form hospital life. In care homes, all the residents will feel is the small day to day kindness or neglect of care assistants on whom they depend for everything.

Yet all too often in the upper reaches of the health department and in the health think tanks, all the focus of the very clever strategy papers they produce is on the next grand plan, the next big idea, deconstructing and reconstructing structures, because structures are things that can be controlled from politicians in Whitehall. That is why the National Health Service (NHS) has suffered 15 major structural reforms in the past 30 years. Far too little attention is given to what happens at the distant ends of their telescopes, on the ground among the humblest employees.

Some of these reforms have been catastrophic for the quality of service the patient experiences at ward level. Of these, the contracting out culture introduced in the 1980s and the 1990s has been the worst. It is taking far too long for this government to grasp that what happens among the lowest paid staff is of critical importance in making the public believe the figures that show the NHS is steadily improving. Keeping them outsourced means they remain outside the blood stream of hospital life.

As a journalist reporting on health and social affairs for most of my life, perhaps I too have been preoccupied with glitzy intellectual ideas at the top-trust hospitals, GP fund holders, now primary care trusts and foundation hospitals. So last year I went to look at these services from the worm's eye view. And was treated like a worm, too.

\section{EXPERIENCE OF WORK AT THE MINIMUM WAGE}

Researching my book, Hard work-life in low pay Britain, ${ }^{1}$ I took six jobs at around the minimum wage, including working as a hospital porter, as a hospital cleaner, and as a care assistant. From my base on a council estate, I searched the computers of the Brixton Job Centre for a job working directly for the state-for the NHS or a local authority. Every time I thought I had found one, it turned out to be working for a contractor, at one remove. Worse, it was often working for an agency that sent me to work for a contractor, at two removes. Until then I had not realised that there are now very few manual jobs left in the direct employ of the state. But these jobs gave me a good insight into why delivery of public services to the public is often so badly done, undermining voters' faith in their progress and quality.

\section{Working as a hospital porter}

The job as a hospital porter in the Chelsea and Westminster Hospital came via an agency down in the east end of London who sent me to work for Carillion, the company that held the cleaning and portering contract. I arrived there with no induction into the noble calling of working for the NHS. I was sent out with another porter for half a day to pick up the basics, but no one tried to give me any sense of the importance of how I treated the patients I was trundling about all day. It was a week before I met even a Carillion supervisor: I never saw anyone connected with the hospital management itself.

By pure coincidence I had been sent back to the same hospital, rebuilt, that I had worked in over 30 years before, in a job at the same grade. The first shock was to discover that I was now 
being paid $£ 36$ a week less, in real terms, than I was then. During three decades, when the gross domestic product had doubled and the country was twice as rich, the wages at the bottom in this hospital had fallen back, not progressed. Thirty years ago I was at least employed by the NHS and hired by the hospital manager who would supervise me. She interviewed me, instructed me in my duties, and kept an eye on my work. This time I was hired by an agency who would take anyone half presentable, few questions asked, no references checked. I could have been a serial unplugger of patient life support machines, or just released from jail or mental hospital.

The next shock was to discover that porters were no longer allowed to lift or even touch patients. How different from 30 years ago when they did all the lifting. Now strong men stood by and watched while frail nurses heaved hefty male patients in and out of beds and wheelchairs. This was because the company was not insured, and so to protect themselves they made it a sackable offence. Here was an example of the many perversities that spring from the contracting culture. We were told not to pick up patients even if they were falling but to let them fall and call for a nurse. How did the patients see this? With perplexity and sometimes distress. Of course we often did lift and help and soothe patients-at our own risk.

Time keeping on the job according to the contract meant we were allocated 15 minutes for each task: often confused or distressed patients took much longer to get in and out of wheelchairs. We had to leave frightened old people, when it would have been kinder to stay and wait with them when they had tests and $x$ ray scans. But we had to refuse. All this is the result of contracts where everything is laid down, every function down sized to its bare bones. An imaginative manager might look at the work of the porters and see ways they could be used better, working in teams with certain wards perhaps, doing extra tasks as the eyes and ears and the oil that wheels the hospital's daily life. But there was no way of altering fixed processes to humanise the porters' time with patients: contracts are more rigid than the old trade union demarcations that were an obstacle to good management in the old days.

Above all, the talents and the intelligence of the porters were wasted. Treated as expendable, replaceable dross, no one thought to invest in their skills. So the NHS lets precious human resources that it needs slip through its fingers at the bottom. The caste mentality fails to see the potential in those they regard, wrongly, as unskilled. This is a self fulfilling attitude: undervalued, few stay long, which makes them not worth investing in. Many of the agency porters were trying to get taken on as permanent staff, but because it would mean the contractor paying them fair overtime rates, they were often refused, and left for better opportunities elsewhere. But above all, it is the contract itself that kills off their opportunities. Why should any contractor up-skill a workforce that would then leave their employ and move on up into the hospital itself? Contracts are the hatches that batten down the workers to keep them in their caste.

Despite their treatment, most of the porters still gave very good service. Many disobeyed the no touching rule and did help patients. They were kinder and more concerned than they were paid to be. Yet the rigidity of the working system, devised by calculator, wastes those caring qualities that would have been well used spending longer with distressed patients who often had to be left alone, uncollected for several hours. When porters saw the system not working, they were not allowed to intervene to rescue a patient: they had to take each job in strict order of rotation. Here as everywhere I worked, the frustration the staff felt was as more directed at the obstructions that stopped them doing their jobs as well as they would have liked, as indignation at their own pay and conditions. This employment policy is no way to engender quality, caring, and pride in a service.

\section{Working as a cleaner}

Working as a cleaner in Guy's and St Thomas' hospital was another illuminating story of bad management, the direct result of contracting out. Starting at $5 \mathrm{am}$, I was assigned 3 hours for a relatively easy cleaning task that could be done well in under 1 hour. Yes, said another worker, this was a good job for students who usually read their books through the other 2 hours. The work had been contracted out for so long that the hospital seemed to have lost touch with how long a cleaning job should take: the contractors had claimed for years that this was a 3 hour job, and so it remained. Hospital managers had become deskilled in how to time cleaning. Now that they were no longer directly employing and timing cleaners, they were plainly at the mercy of the cartels of cleaning companies that ran rough-shod over them. At least the place was clean-but at that price it should be.

\section{Working in a care home}

Everywhere else I worked, the jobs were cruelly under timed, none worse than as a dinner lady where it was impossible to complete the task in the paid hours: the staff often worked unpaid time to finish it. Since writing this, it has been interesting to find that managers always ask me questions about the one over timed cleaning job, and rarely about the under timed jobs. Downsizing is still deep in their mind set, ahead of quality.

I went out of my way to look for good employers and mainstream work places, not hole-in-the-corner worst cases. No doubt I could have found the world's worst employers for all these jobs, but then people would too easily have dismissed my experiences as untypical. So I sought out a good care home, at the upper end of the market, with a fair amount of private as well as state funded residents, and high standards. Hazeldene was the only place that checked all my references before taking me on, the only place that gave me lessons in lifting patients, using hoists, and instructions in basic safety and fire regulations. The supervision was excellent: it would have been hard for any care assistant to have mistreated or neglected a resident unobserved.

But residents of care homes need more than an absence of unkindness. They need the consideration, understanding, and patience that comes from a care assistant knowing residents personally, and their needs. Paid $£ 4.85$ an hour, with nothing extra for working outrageous unsocial hours, we had to work 12 hour days on both Saturday and Sunday every other weekend. So of course there was a rapid turnover of staff on the look out for less stressful and better paid work. This was in the centre of London, with no London weighting allowance and one could not survive on this pay.

None the less, I was struck by how much these women gave the residents. It was physically exhausting work, but above all it drained their emotions. Many of the residents were understandably depressed, and needed cheering and comforting at the lonely end of their days. They depended on their carers for every little thing, their lives easily made intolerable if left too long in bed or too long on a commodeand the care assistants gave their all for little remuneration. In the long run, though, quality in a home depends on staff who stay and build a bond with the residents: low pay leading to high turnover will always mean lower quality for vulnerable residents.

\section{DISCUSSION}

So here were jobs at the sharp end, up close and very personal to the patients, strongly influencing their experiences of the services they were using. Yet these are low paid, under valued jobs that fall below the radar of the policy makers. In 


\section{Key messages}

- Paying these people more would cost more, but it would also harvest great rewards by using their untapped commitment.

- Creative managements should be looking at these high turnover jobs and seeing the employees in their true potential for providing far higher quality.

- More trust and responsibility of these people would help tap their unused commitment and skill.

- Contracted work in hospitals needs to be brought back in-house and integrated into a team ethos.

- Quality in a care home depends on staff who stay and build a bond with the residents: low pay leading to high turnover will always mean lower quality for vulnerable residents.

hospitals they need to be brought back in-house and integrated into a team ethos. Paying these people more would cost more, but it would also harvest great rewards by using their untapped commitment. Creative managements should be looking at the swathes of people who come and go in these high turnover jobs and seeing in them their true potential for providing far higher quality. They are willingbut they have to be paid a living wage. The dividend would be in staff development, a sense of cohesion and a united front in the holistic treatment of the public: contracting out reduces service to a series of minimum tick boxes.
As the demographics increasingly point to a shortage of labour, it will become ever more important to value and make best use of the labour available. Politicians talk of the need for upskilling the workforce: what struck me was how the intelligence and aptitudes of these people is underrated, simply because they lack formal qualification. In truth, it would take very little beyond the opportunity to move them up the scale of responsibility: it is partly qualification obsession that holds them down. Quality in these services is not necessarily to be found in national vocational qualifications. Face to face good treatment of patients will often count for more when it comes to making the public feel they are getting high standard public services.

We hear so much cant these days about trying to make bottom up not top down change. But the bottom rarely means those scrubbing the floors. Ask them, and very often they know how they could make their own work more fulfilling, and produce better results for the end users. A little more trust in those of the untouchable class would be refreshing and rewarding for managers. At the top, it means rethinking the whole contracting out culture: until I did these jobs myself, I had not appreciated the depth of damage done by separating out these workers from the main body of the institution and its purposes. Squeezing their pay and conditions makes short term savings, but only at the cost of long term loss in quality.

\section{Author's affiliation}

P Toynbee, The Guardian, 119 Farringdon Road, London ECIR 3ER, UK

\section{REFERENCE}

1 Toynbee P. Hard work-life in low pay Britain. London: Bloomsbury, 2003. 